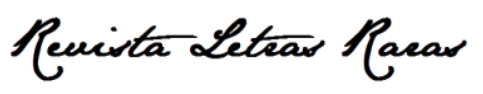

ISSN: 2317-2347 - v. 9, n. 3 (2020)

Todo o conteúdo da RLR está licenciado sob Creative Commons Atribuição 4.0 Internacional

\title{
Referenciação fílmica em Barba ensopada de sangue,
}

\author{
de Daniel Galera /
}

\section{Filmic Referencing in 'Blood-Drenched Beard', by Daniel Galera'}

\begin{abstract}
Cristiane Fickelscherer de Mattos *
Possui Graduação em Letras pela Faculdade de Filosofia, Letras e Ciências Humanas da Universidade de São Paulo (USP) - 1986-, Licenciatura em Letras pela Faculdade de Educação da Universidade de São Paulo (USP) - 1987-, Mestrado em Letras pela Faculdade de Filosofia, Letras e Ciências Humanas da Universidade de São Paulo (USP) 1993- e Doutorado em Letras pela Faculdade de Filosofia, Letras e Ciências Humanas da Universidade de São Paulo (USP) - 2004. Atualmente é professora da Universidade Presbiteriana Mackenzie (graduação e pós-graduação). Tem experiência nas áreas de Letras, Comunicação, Artes, Teatro e Música. Desenvolveu pesquisa - para o mestrado e 0 doutorado - em literatura, semiótica e análise do discurso. Atualmente trabalha com a aplicação dos pressupostos teóricos dessas áreas à literatura, à comunicação jornalística e publicitária e à produção editorial. É membro dos grupos de pesquisa do CNPq: "Intermídia: estudos sobre intermidialidade" (UFMG), "Literatura no contexto pósmoderno" (Universidade Presbiteriana Mackenzie). É Editora da "Todas as Letras - Revista de Língua e Literatura", revista acadêmica da Universidade Presbiteriana Mackenzie - UPM; filiada à Associação Nacional de Pós-Graduação em Letras e Linguística (ANPOLL), à Associação Brasileira de Literatura Comparada (ABRALIC); à International Comparative Literature Association (ICLA).
\end{abstract}

iD https://orcid.org/0000-0003-2011-4614

Recebido em: 01 jun. 2020. Aprovado em: 28 jun. 2020.

\section{Como citar este artigo:}

MATTOS, Cristiane Fickelscherer de. Referenciação filmica em Barba ensopada de sangue, de Daniel Galera. Revista Letras Raras. Campina Grande, v. 9, n. 3, p. 40-57, ago. 2020.

\section{RESUMO}

Este artigo tem por objetivo estudar a intermidialidade presente no romance Barba ensopada de sangue, do escritor brasileiro contemporâneo Daniel Galera. 0 estudo parte da hipótese de que a obra se expressa e se organiza por meio de uma referenciação fílmica, proposta aqui como designação para a relação específica, entre o cinema e a literatura que trabalha intermidiaticamente por referenciação - como a definiu Irina Rajewsky (2012) -, mas o faz privilegiando a parte visual. 0 trabalho examina também a recepção crítica da obra no que diz respeito a análises de aspectos seus relacionados à linguagem filmica. As reflexões de Gilles Deluze em seus Imagem-movimento (1983) e Imagem-tempo (1985) fornecem a fundamentação teórica sobre as características dessa linguagem nascida com 0 cinema e amplamente praticada por outros meios nos dias de hoje. O trabalho visa contribuir com os estudos sobre as relações entre cinema e literatura, menos desenvolvidos que as relações entre literatura e cinema, mormente

1 GALERA, Daniel. Blood-Drenched Beard. New York: Penguin Press, 2015.

cristiane.mattos@mackenzie.br 


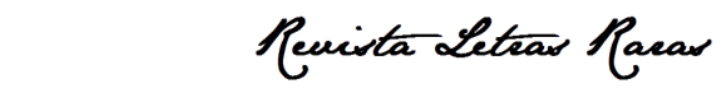

ISSN: 2317-2347 - v. 9, n. 3 (2020)

Todo o conteúdo da RLR está licenciado sob Creative Commons Atribuição 4.0 Internacional

menos que a adaptação. Por fim, esta análise espera enriquecer o conhecimento sobre a literatura brasileira contemporânea.

PALAVRAS-CHAVE: Referência intermidiática; Daniel Galera; Referenciação fílmica.

\section{ABSTRACT}

This paper aims at studying the use of intermedial writing in the novel Blood-Drenched Beard, by contemporary Brazilian writer Daniel Galera. It assumes that the novel expresses and organized itself through a filmic referencing, proposed here as term to indicate the specific relation between cinema and literature that works through intermedial referencing - as defined by Irina Rajewsky (2012) - by highlighting the visual component. The study also examines the critical reception of the novel with regard to its filmic language. Gilles Deleuze considerations in his Movement-image (1983) and Time-image (1985) provide the theoretical foundation on the characteristics of this language, born with cinema and widely used by other media today. This paper intends to further the thinking on the relationship between cinema and literature that seems to have had much less attention than the reversed relationship between literature and cinema, especially less than adaptation from book to screen. Finally, this study hopes to broaden some general knowledge about Brazilian contemporary literature.

KEYWORDS: Intermedial reference; Daniel Galera, Filmic Referencing.

\section{Introdução}

O romance Barba ensopada de Sangue, de Daniel Galera, publicado em 2012, teve grande repercussão nos meios de comunicação e provocou instigantes reações críticas, por vezes, bastantes contraditórias entre si, ora enaltecendo a obra como significativa representante da literatura contemporânea ora menosprezando-a como produto menor repleto de falhas. Com o anseio de aprofundar tais análises e descobrir os motores dos contrastes de leitura que a obra suscitou, este trabalho postula a hipótese de que o romance expressa-se e organiza-se por meio do que aqui designaremos por referenciação fílmica. A esse fato estariam ligados os desencontros de recepção do texto.

A referenciação fílmica, entendida como relação entre o cinema e a literatura e, mais especificamente, como referência intermidiática - segundo definição de Rajewsky (2012) - que privilegia o teor visual da linguagem cinematográfica, constitui-se uma expressão, em linguagem própria do meio literário, dos modos constitutivos do narrar fílmico, isto é, uma maneira literária de narrar "como se víssemos um filme". O termo "fílmica", anexado a "referenciação", nasce da necessidade de indicar o trabalho literário de inserção da linguagem cinematográfica pelo seu teor visual em separado de seu teor sonoro. ${ }^{2}$ Embora imagem e som estejam sempre conjugados

\footnotetext{
2 O teor visual destacado na literatura tem recebido, ao longo dos tempos, as mais diferentes designações e teorizações. Em muitos estudos, confundem-se os componentes meramente pictóricos com os da imagem em movimento (ou da linguagem cinematográfica que promove a ilusão do movimento). As ponderações que enfocam especificamente 0 diálogo do filme com 0 texto literário também adotam uma vasta gama de expressões
} 


\section{Penista Letraw Parar \\ ISSN: $2317-2347-$ v. 9, n. $3(2020)$ \\ Todo o conteúdo da RLR está licenciado sob Creative Commons Atribuição 4.0 Internacional}

atualmente, a literatura, historicamente, tem apelado mais à visualidade cinematográfica que à sua sonoridade. ${ }^{3} \mathrm{O}$ artigo tem por objetivo, portanto, estudar o texto e examiná-lo à luz de teorias e conceitos relativos à linguagem fílmica que permitam a identificação e a compreensão desse tipo de intermidialidade no romance de Galera.

A formulação dessa hipótese apoiou-se tanto nas impressões de leitura da obra quanto na sua confluência com outras obras do autor em que o teor fílmico faz-se notar. Para ver apenas dois exemplos, destaco que Galera roteirizou (de fato) a narrativa da graphic novel intitulada Cachalote em 2010, na qual predominam quadros sem qualquer expressão verbal, semelhantes, por isso, a storyboards. Em outra obra - Mãos de cavalo, de 2006 -, a narração menciona explicitamente o meio cinematográfico e sua linguagem fílmica:

Sua imaginação trabalhava como se projetasse um filme, cortando a luta encarniçada em planos, coreografando cada golpe e abusando da câmera lenta. [...] Às vezes a câmera surgia nos instantes cruciais de sua existência, às vezes captava a realidade de momentos banais e solitários [...] Não era simplesmente sentir-se observado, imaginar testemunhas indefinidas para cenas de sua vida. Era como se ele mesmo se destacasse do corpo para se tornar o observador. Era ele quem operava a câmera, quem saía da cena, atravessava a membrana entre a realidade e a imaginação e escolhia uma cadeira na plateia vazia de um cinema escuro (GALERA, 2016, p. 139-40).

A linguagem fílmica, que nesse romance anterior se insere como uma particularidade da imaginação do personagem, irá revelar-se elemento estruturador na obra que aqui analisamos, publicação posterior.

Estudos sobre a narrativa do século XXI estão ainda em curso de produção. Os modos narrativos que the correspondem dialogam certamente com o contexto em que é produzida e com as heranças que recebe do passado. O século XX viu difundirem-se e nascerem muitos meios de comunicação que foram gradualmente convergidos para o meio digital. Em meio a essas mudanças, o sujeito transformou-se inevitavelmente. Compreender os modos narrativos do século XXI é também compreender como a literatura retrata a relação entre os meios que resulta dessa

(SCHWANECKE, 2015). Em português, usa-se comumente o termo "cinematográfico", com o qual se refere o todo do meio cinema, em sua dinâmica audiovisual. Como em muitos romances, em Barba ensopada de sangue, a parte visual fílmica se sobressai fortemente sobre qualquer referência sonora, de modo que seria impreciso dizer que nessa e em outras obras literárias há "referenciação cinematográfica". Assim, o conceito de "referenciação fílmica" aqui empregado designa tanto a relação intermidiática com o cinema quanto a específica dinâmica expressiva das imagens em movimento.

${ }^{3} \mathrm{~A}$ prevalência do imagético na contemporaneidade vem sendo postulada por abordagens teóricas desde o século XX como a de uma "cultura visual" ligada a toda uma "visualidade literária" (RIPPL, 2015, p 19). Estudos sobre uma cultura acústica e sua emergente presença na literatura são mais recentes (SCHWEIGHAUSER, 2015). 


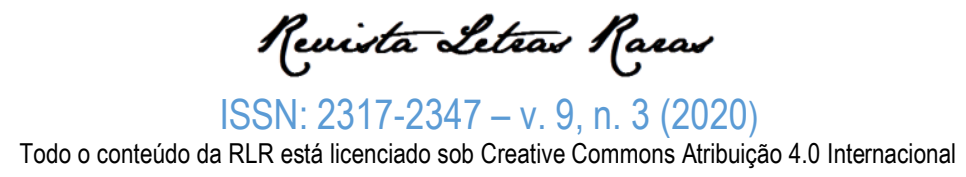

convergência, como entende o sujeito que a vive em suas maneiras de conceber o tempo e 0 espaço.

\section{Intermidialidade e contexto}

Dentre as muitas novas formas de expressão surgidas nos últimos 200 anos destacam-se as que articulam imagens em movimento. Em 1990, ponderando sobre as transformações que 0 universo da técnica ocasiona nas maneiras de pensar e conviver, Pierre Levy, em seu livro Tecnologias da inteligência, ressaltou o quão próximo estávamos então de reunir "todas as condições técnicas para que 0 audiovisual atinja o grau de plasticidade que fez da escrita a principal tecnologia intelectual" dos últimos tempos (LÉVY, 2004, p. 103). Gilles Deleuze, em seu longo estudo sobre o cinema, realizado entre 1983 e 1985, já havia relacionado a evolução da linguagem cinematográfica à gradual introdução de uma nova articulação do pensamento a essa linguagem apensa (DELEUZE, 1985 e 2004).

O sequenciamento imagético, que nasce no cinema, expande-se com a introdução da banda sonora nos filmes, diversifica-se, adiante, com o desenvolvimento da televisão e do VHS (como linguagem audiovisual expressa por mais de um meio comunicação) e, mais tarde, com a difusão operada pela tecnologia digital (como recurso audiovisual presente em quase todos os meios e dispositivos de comunicação do cotidiano). A prevalência do audiovisual no mundo contemporâneo possui inevitáveis consequências, dentre as quais está aquela que possibilita 0 objetivo deste trabalho: investigar a presença de referências midiáticas fílmicas na escritura literária de um romance contemporâneo. Como se verá adiante, no caso específico de Barba ensopada de sangue (2012), do escritor brasileiro Daniel Galera, é apenas a parte imagética cinematográfica que se sobressai na escrita literária. ${ }^{4}$

Das relações possíveis entre literatura e linguagem audiovisual, a mais estudada até hoje tem sido a adaptação de narrativas verbais para a linguagem cinematográfica. Como 0 demonstram as considerações pioneiras de André Bazin (1952) e as expandidas ponderações de

\footnotetext{
${ }^{4} \mathrm{~A}$ presença de referências à sonorização cinematográfica não se faz sentir no romance de maneira destacada. Por isso o trabalho se atém a referências visuais próprias da linguagem fílmica. Embora imagem e som estejam essencialmente articulados no cinema atual, os elementos conceituais da linguagem cinematográfica a fundamentar a análise, extraídos das reflexões de Deleuze (1983 e 2005), estabeleceram-se, segundo ele, antes da inserção da banda sonora nos filmes.
} 


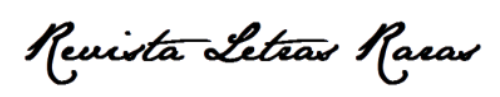

ISSN: 2317-2347 - v. 9, n. $3(2020)$

Todo o conteúdo da RLR está licenciado sob Creative Commons Atribuição 4.0 Internacional

Linda Hutcheon (2006), englobando outros meios além do cinema, no que diz respeito aos intercâmbios entre linguagens, as atenções sempre estiveram majoritariamente direcionadas das mídias impressas (mormente, do livro) para as mídias audiovisuais. Essa tendência predominante suplantou observações no direcionamento contrário, isto é, do audiovisual para o impresso, mesmo quando proferidas por grandes teóricos do cinema como Eisenstein em 1937 (EISENTEIN, 2002b) e Bazin em 1952 (BAZIN, 1991, p. 88), ou por acadêmicos como Magny (1949) e Murray (1972). Certamente, a razão para a atenção desproporcional dada a um vetor em detrimento do seu contrário nas relações entre páginas e telas, reside no desenvolvimento desigual de reflexões teóricas a respeito dos processos intermidiáticos envolvidos. Adaptações de narrativas literárias para o cinema ou qualquer meio audiovisual vêm gerando teorizações específicas há bastante tempo, com textos seminais do início do século XX - como os de Béla Balázs (2011), escritos nos anos 1920, ou os de Sergei Eisenstein (2002a), dos anos 1940 -, até as mais recentes contribuições do século XXI - como as de Robert Stam (2006) e Linda Hutcheon (2006). Já o vetor contrário, não conheceu produção teórica nem de longe semelhante, em extensão e profundidade, a essa das adaptações. Ao historiar os estudos desse segundo vetor, Christine Schwanecke (2015) mostra-nos que a partir dos anos 60, a crítica atentou para a presença do fílmico na literatura, mas ainda foi preciso esperar os anos 90 para que problemas conceituais que obstruíam o desenvolvimento desses estudos começassem a ser superados e permitissem, apenas na virada do milênio, análises efetivas.

Há que se destacar, no entanto, que os dois vetores possuem naturezas distintas, pois enquanto o romance que vira filme trabalha com o conteúdo da obra literária como um todo, no sentido inverso, o cinema que vira literatura ocupa-se, em geral, nas palavras de Bazin, "de referências cinematográficas", entendidas como "procedimentos [cinematográficos] com os quais o escritor constrói seu universo particular" (BAZIN, 1991, p 89). Filmes cuja mensagem total é transposta para as páginas de um livro possuem caracterização diversa. Tal o caso da produção cinematográfica O labirinto do fauno (Pan's Labyrinth, 2006), longa-metragem de roteiro original do diretor Guillermo del Toro que foi convertido em livro de mesmo nome, redigido pela escritora Cornelia Funke e publicado em 2019. Convém destacar o fato de que não se trata de publicação impressa do roteiro do filme, mas de romancização do filme. Essa adaptação às avessas, contudo, 


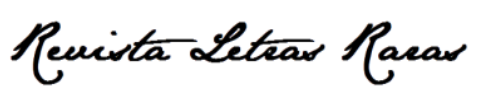

ISSN: $2317-2347-$ v. 9, n. $3(2020)$

Todo o conteúdo da RLR está licenciado sob Creative Commons Atribuição 4.0 Internacional

tem se mantido distante dos interesses da crítica por uma série de razões - como o comenta Jan Baetens (2008) - e aguarda ainda melhores pesquisas e teorizações. ${ }^{5}$

A relação filme-livro concebida como referência cinematográfica presente em romances ou narrativas em geral, por sua parte, experimentou no final do século XX, certo impulso por meio dos chamados Estudos Interartes, dedicados às relações entre literatura e outras expressões artísticas. Dos desafios das análises comparadas entre poesia e fotografia, romance e pintura, entre outras, originou-se, por fim, um instrumental teórico capaz de diferenciar conceitualmente os tipos de relações entre os meios de comunicação: a intermidialidade. Devido ao caráter recente de suas postulações, o vasto campo de aplicação da perspectiva teórica intermidiática vem aos poucos agregando contribuições analíticas. $O$ presente trabalho procura acorrer nesse sentido, além de colaborar também com o desenvolvimento dos estudos sobre a literatura brasileira contemporânea.

\section{Prosopagnosia narrativa}

A leitura de Barba ensopada de sangue experimenta surpresas logo nas primeiras páginas. Uma narrativa tradicional em primeira pessoa - marcada graficamente pela formatação em itálico - introduz o leitor num universo que se altera abruptamente em seguida pela perda do itálico e com o surgimento de uma escrita ecfrástica de elementos justapostos, articulados por um único e diminuto verbo inicial em terceira pessoa:

Vê um nariz batatudo, reluzente e esburacado como uma casca de bergamota. Boca estranhamente juvenil entre queixo e bochechas tomados por rugas finas, pele um pouco flácida. Barba feita. Orelhas grandes com lóbulos maiores ainda, parecendo esticados pelo próprio peso. Íris da cor de café aguado no meio de olhos lascivos e relaxados. Três sulcos profundos na testa, horizontais, perfeitamente paralelos e equidistantes. Dentes amarelados. Cabelos loiros abundantes quebrando numa única onda por cima da cabeça e escorrendo até a base da nuca. Seus olhos percorrem todos os quadrantes desse rosto no intervalo de uma respiração [...] (GALERA, 2012, p. 13).

A descrição fragmentada, que impõe ao leitor uma montagem diacronicamente gradual do rosto visto pelo personagem, encontra explicação imediatamente depois quando o narrador

\footnotetext{
${ }^{5}$ Há que se destacar que a romancização de filmes é tema controverso, pois para muitos, confunde-se com a ação publicitária geral de promoção do filme (MAHLKNECHT, 2012). Tal o caso, por exemplo, da histórica romancização do roteiro do filme King Kong, escrita por Delos W. Lovelace e lançada em 1932, antes da estreia do filme em 1933.

doi http://dx.doi.org/10.35572/rlr.v9i3.1866
} 


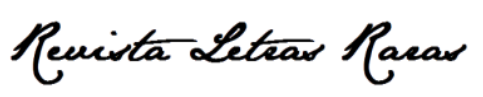

ISSN: 2317-2347 - v. 9, n. 3 (2020)

Todo o conteúdo da RLR está licenciado sob Creative Commons Atribuição 4.0 Internacional

declara que, embora o personagem possa jurar nunca ter visto na vida a pessoa cujos fragmentos de rosto contempla, ele "sabe que é seu pai porque ninguém mais mora nessa casa desse sítio em Viamão e porque ao lado direito do homem sentado na poltrona está deitada de cabeça erguida a cadela azulada que o acompanha faz muitos anos" (GALERA, 2012, p.13). E assim inicia-se a narrativa sobre um jovem professor de educação física acometido de prosopagnosia (incapacidade neurológica de memorizar rostos) que, depois do suicídio do pai, tendo de cuidar da cachorra deste, resolve partir rumo à cidade de Garopaba para refazer-se do ocorrido e esquecer a exnamorada, que se casou com seu irmão. Numa busca por compreender a si mesmo e suas relações com a família, o protagonista, cujo nome não sabemos, procura descobrir informações sobre seu misterioso avô, pai de seu pai, que vivera nessa localidade.

Para nos contar essa história, o romance de Galera usa muitos diálogos e descrições, algumas delas fragmentadas como a que foi citada acima. Esse modo descritivo particular está relacionado ao problema neurológico do protagonista, mas o leitor só o saberá no segundo capítulo, quando o narrador menciona "sua incapacidade de memorizar qualquer rosto humano por mais que alguns minutos" (GALERA, 2012, p. 43-44). O foco narrativo é também bastante inusitado: trata-se, na maior parte do tempo, de uma terceira pessoa onisciente que, no entanto, funciona como primeira, por estar totalmente centrada na percepção do protagonista. Há, contudo, outras pespectivas de narração, em forma de paratextos em primeira pessoa, sempre marcadas graficamente: no início, como já mencionado, e também em diálogos unilaterais, dispostos como notas de rodapé. A percepção a respeito do paralelismo narrativo dessas partes ocorre gradualmente, conforme o leitor vai obtendo informações e estabelcendo conexões. $O$ paratexto incial revela-se extradiegético, inferido pela leitutra como fonte de inspiração da realidade para a criação da obra ficcional. Os paratextos posteriores surgem em meio a trechos do romance que levam o leitor a concluir que seja a voz de outros personagens em interlocução com alguém cujas palavras não são exibidas, mas que conversam sobre o protagonista.

A fragmentação da narrativa ocorre, assim, dentro da perspectiva do protagonista e também fora dela. $O$ narrador em terceira pessoa que, no entanto, descreve apenas ações $\mathrm{e}$ pensamentos do protagonista e de tudo que ele vê, mistura objetividade e subjetividade sem encaixar-se totalmente em qualquer foco narrativo consagrado, mesmo entre os mais contemporâneos, como o discurso indireto livre ou modo câmera de narrar. A restrição de perspectiva do narrador coloca o leitor na pele do protagonista cuja visão interna da realidade percebida está parcialmente impedida pela doença neurológica que possui. O leitor acompanha 0 


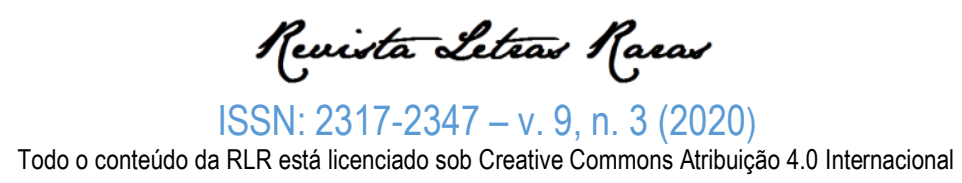

desenvolvimento do enredo buscando, como o seu personagem principal, um sentido para as páginas vividas.

\section{Aspectos da Crítica do Romance}

As inovações da narrativa de Galera em Barba ensopada de sangue chamaram a atenção da crítica desde o seu lançamento. Para uma obra recente de um escritor jovem, o romance produziu uma quatidade significativa de críticas em geral e recebeu uma atenção particular da academia. As considerações crítico-analíticas, porém são bastante diversificadas. Há consenso e afinidade a respeito de alguns fatores, dissenso e conflito em relação a outros. Entre os primeiros podemos destacar que quase todos os críticos apontam uma visualidade excessivamente destacada pelo texto (SANTOS, 2012; GRANDO e FURTADO, 2018; ASSIS, 2014; FACHIN, 2015); que alguns ressaltam uma semelhança com a linguagem roteirística (ANA, 2013; CUNHA, 2011; LETOUZÉ, 2019) ou cinematográfica (FIGUEIREDO, 2012; SCHØLLHAMMER, 2009; LETOUZÉ, 2019); enquanto outros identificam uma oscilação entre objetividade e subjetividade na expressão textual (SCHØLLHAMMER, 2012a e 2012b; ASSIS, 2014; ANA, 2013; FACHIN, 2015). Já entre os fatores conflitivos evidenciados pela crítica ao romance, é forçoso ressaltar a percepção de conformidades e desconformidades com a estética do realismo, devido a uma "estranha combinação entre representação e não representação" (SCHØLLHAMMER, 2012b, p. 129) ou devido ao paradoxo de uma literatura que manifesta um "realismo íntimo" ou "realismo afetivo" (SCHØLLHAMMER, 2012a e 2012b; ASSIS, 2014); a percepção de um teor emocional prometido, que no entanto a obra não chega a alcançar (VIGNA, 2012); de um uso excessivo de descrições que não alimentam o universo ficcional (ANA, 2013).

Ao lado de elogios da crítica e do Prêmio São Paulo de Literatura em 2013, como "melhor livro do ano", Barba ensopada de sangue obteve leituras analíticas mordazes e desdenhosas. Como é amplamente registrado pela história das artes ou da literatura, é comum que as novidades causem adesões e rejeições num primeiro momento. A partir da experiência de leitura da inusitada forma de narrar no romance e das intrigantes colocações da crítica a seu respeito, surgiu a hipótese crítico analítica deste trabalho: estamos diante de uma literatura que se comporta como se pertencesse a outro meio e comunicação, que se faz "como se fosse" linguagem fílmica, absorvendo seus processos de produção que incluem o primado da imagem, a ilusão da não- 


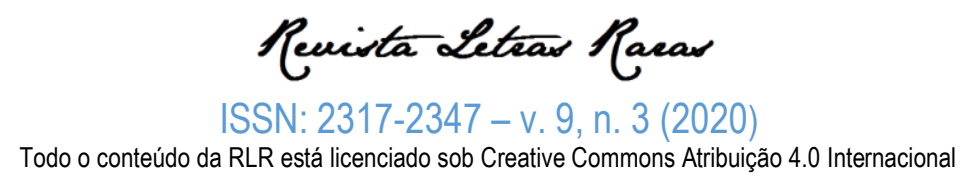

representação, a subjetividade vista e ouvida, o roteiro e a decupagem. Essa referência intermidiática fílmica na literatura vai além de uma mera incorporação técnica ou de um recurso discursivo adotado para fins estilísticos, pois constitui-se fundamento mesmo da mimesis textual. A representação no livro se concebe como verbalização de imagens vistas ou mentalizadas pelo protagonista, como quem narrasse um filme que passa pela cabeça. Há um lapso entre a captação das imagens pela visão e a sua concatenação verbalizada, em função da deficiência do protagonista, lapso que encontra na linguagem fílmica a justa correspondência entre o registro das imagens pela câmera e seu processamento de montagem. O foco narrativo está, assim, perfeitamente integrado ao universo ficcional, justificado internamente pela condição neurológica do personagem ao qual está aderida sua perspectiva. A existência de outros focos narrativos nos paratextos mencionados encontra também pontos de convergência com a condição neurológica e com a linguagem fílmica. Não reconhecer as pessoas permite ao personagem mover-se por uma realidade paralela como a desses textos, alheia à relação estabelecida com as pessoas, como se estivesse inserido em outro contexto. Saltar de um contexto para outro, de uma perspectiva para outra é expediente próprio possibilitado pelo cinema tanto pela montagem paralela, introduzida por Griffith, quanto pela montagem alternada, desenvolvida para eventos concomitantes ou, ainda, pela decupagem em plano e contraplano (shot/reverse-shot, BORDWELL; THOMPSON, 2008, p. 235), usada para expressar as perspectivas em contraste nas relações entre personagens. No que diz respeito ao desenvolvimento do enredo, a obra manifesta também aspectos de um pensamento cinemático contemporâneo e uma consciência da recepção desse pensamento. Para adentramos essa questão, fazem-se necessários alguns apontamentos teóricos sobre a linguagem fílmica.

\section{Percepção e subjetividade intermidiáticas}

Como afirma Rajewsky, a referência intermidiática pode aludir a uma obra específica, a um subsistema midiático (como um gênero) ou a outra mídia como sistema semiótico-comunicativo (RAJEWSKY, 2012, p 25). No caso de Barba ensopada de sangue, estamos diante do terceiro tipo, pois como exposto acima, o romance trabalha variados níveis e aspectos da linguagem fílmica. Através do literário, acessamos, além da parte técnica mais palpável desse sistema, também sua particular conjunção de tempo e espaço, identificada por Deleuze como imagempensamento. 


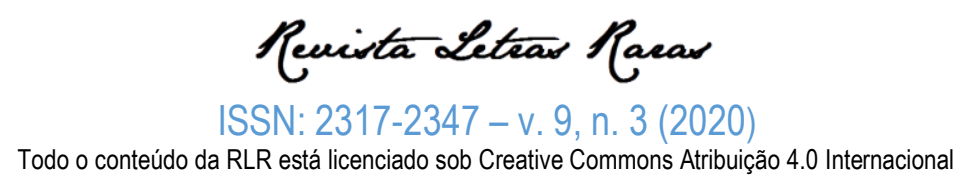

Segundo suas reflexões, o nascimento do cinema se dá na vigência da ilusão perceptiva de apreensão do todo, a partir de uma perspectiva humana autocentrada. Com base nas reflexões de Bergson - que afirmam a impossibilidade da percepção de elementos da realidade para além de sua manifestação estática espacial (recortes instantâneos da realidade que vão sendo processados cognitivamente) e revelam ser quimérica a existência de percepções comuns a todos os seres humanos que processem verdadeiramente a totalidade do movimento, devido à inclinação figurativa de nossos processos mentais -, Deleuze nos mostra o desenvolvimento do cinema como fator de conscientização dos processos perceptivos (DELEUZE, 1985).

No amanhecer da comunicação filmica, os expedientes utilizados procuravam reproduzir os modos ilusórios da percepção humana totalizadora: como um teatro filmado, a câmera fixa correspondia à posição de um observador que, captando e processando parte a parte o percebido, pressupunha a apreensão do movimento e a inferência da realidade como um todo. A despeito da constituição técnica do filme ser tão parcial e ilusória quanto a percepção bergsoniana, isto é, formada por fotogramas exibidos sequencialmente a uma velocidade superior à capacidade de seu processamento por nossas retinas, todo o empenho comunicativo inicial do novo meio está destinado à manutenção dos hábitos perceptivos humanos. A experiência do cinematógrafo, no entanto, ao expor o homem à reprodução externa e artificial de seus próprios processos perceptivos, descortina e inverte os automatismos da relação do sujeito com a realidade: "[0 cinema] não se confunde com as outras artes, que visam antes um irreal através do mundo, mas faz do próprio mundo um irreal ou uma narrativa: com o cinema, é o mundo que se torna sua própria imagem, e não uma imagem que se torna o mundo" (DELEUZE, 1985, p. 59).

Devido à simultaneidade da comunicação imagética e à sua natural dispersão perceptiva (onde focar? em qual ordem observar os muitos signos comunicados por uma imagem?), acrescida, no cinema, da contínua sucessão de tomadas e cenas, ao longo dos anos de comunicação cinematográfica, o trabalho da câmera foi aos poucos se alterando e passou a recortar o campo de visão para direcionar a observação dos espectadores. A linguagem cinematográfica foi, então, estabelecendo expedientes próprios de articulação - recorte pelo enquadramento, ângulo de visão, escolha de ações e de sequenciamento - que revelam, de forma cada vez mais explícita, os processos inerentes à percepção humana, momentânea ou passada, sobre os quais não havia (e ainda não há, embora menos intensamente) qualquer consciência formal. 


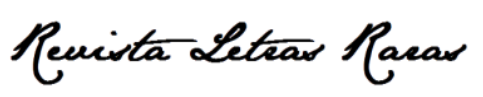

ISSN: 2317-2347 - v. 9, n. 3 (2020)

Todo o conteúdo da RLR está licenciado sob Creative Commons Atribuição 4.0 Internacional

A reprodução técnica desses processos alterou também a compreensão sobre a dicotomia objetividade versus subjetividade. Segundo Deleuze, a percepção humana, de forma semelhante aos expedientes técnicos, realiza recortes de atenção na realidade, define ângulos, destaca ações e escolhe sequenciamentos de fatores para sobre eles agir a cognição. São esses procedimentos perceptivos que determinam a subjetividade, operando por subtração, ao excluir tudo que não interessa à percepção do sujeito (DELEUZE, 1983, p. 66). Por contraste, a objetividade liga-se à ausência de tais subtrações, isto é, à ilusão da percepção do todo, a uma pretensa possibilidade de não-escolha entre os infinitos elementos da realidade a serem registrados. A subjetividade estaria, assim, ligada à presença de um centro organizador que estabelece opções e ordenamento limitadores, direcionando o entendimento de uma imagem à outra. Estaria também muito mais presente nas narrativas ficcionais (com complexidades crescentes ao longo da história do cinema), que nas narrativas documentais, nas quais almeja-se a objetividade pela maior exclusão possível de procedimentos de subjetivação. Do mesmo modo que com os processos perceptivos, a difusão dos expedientes de subjetivação do cinema alterou os níveis de consciência sobre eles.

A narrativa imagética de Daniel Galera em Barba ensopada de sangue, absorvendo os expedientes fílmicos como referência intermidiática, trabalha sobre os modos de percepção da personagem (dentro do universo ficcional) e dos leitores (fora dele). Por meio do problema neurológico do protagonista, usado como recurso de verossimilhança, torna-se aceitável um foco narrativo romanesco que, tal como no cinema, explicita os modos de percepção humanos, recortando e escolhendo elementos da realidade para conduzir a leitura pela subjetividade desse personagem sem nome. Como no cinema - em que um protagonista não será aquele a empunhar a câmera, mas aquele que a câmera focaliza -, escolhendo enquadramentos e ângulos que melhor transmitam sua subjetividade, no romance de Galera, o personagem cuja trajetória acompanhamos não toma a palavra para narrar. A percepção e a subjetividade cinematográficas, hoje convertidas em percepção e subjetividade audiovisuais, presentes nos meios digitalmente convergidos, ao serem praticadas no meio literário com os expedientes expressivos que lhe são próprios - terceira pessoa narrativa -, causam um desconcerto de leitura que pode explicar os contrastes crítico-analíticos já referidos. Trechos como o que abre o romance jogam metaficcionalmente com a referência intermidiática fílmica ao justapor imagens que o personagem registra, mas não processa, como se fossem fotogramas contemplados em uma fita de celuloide ou takes arquivados em gravação digital que carecem ainda de montagem e edição. Ao leitor é delegada provisoriamente essa função de articulação entre as imagens, antecipando as conexões 


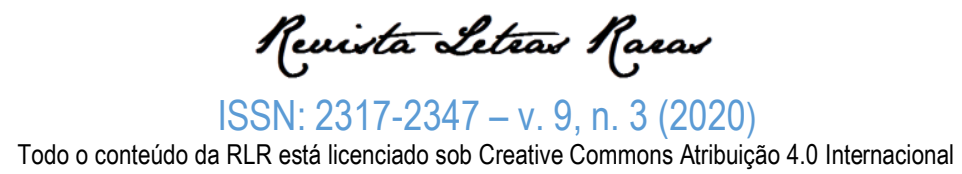

de sentido que a narrativa estabelecerá mais adiante. Da mesma forma que na sequência do fragmento de abertura, em que a justaposição de imagens desconexas ganha articulação e sentido pelo reconhecimento da cachorra e, consequentemente, do pai, na sequência abaixo encontramos o mesmo processo:

Procura os cabelos crespos, a garçonete de maior estatura. Devia ter perguntado seu nome. Há cabelos crespos de sobra por aí. Em sua lembrança, agora, o rosto dela é uma caricatura quase abstrata de pinceladas aguadas. Mas ele a reconhece pela postura. [...] Tinha achado ela bonita, esse fato permanece, mas o conteúdo da beleza tinha se perdido e agora é recuperado. É como se a visse pela primeira vez. (GALERA, 2012, p. 48)

Depois da desorientação perceptiva inicial, um elemento de coesão - a postura possibilita a conexão dos fragmentos percebidos. Em seguida, o narrador nos mostra o prejuízo que a deficiência causa em sua subjetividade: a imagem perdida da moça apagara também seu entendimento, seu julgamento. O personagem terá de começar a apreciação do percebido novamente.

Ao longo de todo o romance, o leitor se depara com percepções desconexas que encontram explicação em seguida. Essa maneira de dispor elementos no desenvolvimento da narrativa confere certa expectativa à compreensão do que acontece com o personagem em situações específicas. Como a deficiência impede escolhas e deduções perceptivas por parte do personagem, sua subjetividade fica prejudicada interna e externamente, isto é, fica dificultada para o próprio personagem - que se mostra perdido em suas opiniões, sentimentos e decisões - e para o leitor - que não sabe o que esperar dos rumos de uma história com partes desconectadas pela desorientação do protagonista. Essa subjetividade truncada acaba por outorgar boa dose de suspense à obra como um todo.

\section{Narrar com imagens}

Os estudos de Deleuze sobre a linguagem do cinema acima citados pertencem à obra Imagem-movimento, de 1983. Aprofundando a visão crítica, dois anos depois, o mesmo autor publicou o volume Imagem-tempo (1985), no qual afirma que o amadurecimento do meio e sua relevância cultural, ademais de novos aportes técnicos, ocasionou uma alteração na própria função representativa de sua linguagem. Se antes, a percepção e a subjetividade de um filme, 


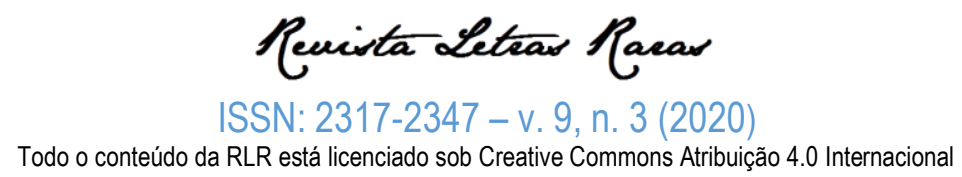

sendo semelhantes à percepção e à subjetividade humanas em geral, apenas as explicitavam, a meados do século $X X$, segundo Deleuze, as produções cinematográficas abriram caminho para novas formas de apreender e sentir. O primeiro cinema, ciente de suas inevitáveis rupturas essenciais (fotogramas, decupagem e montagem), ocupou-se em estabelecer liames que criassem a ilusão da continuidade e da totalidade, a exemplo do que faz a literatura tradicional por meio da linguagem verbal, costurando aspectos esparsos da realidade com a ação dos personagens. Pode-se dizer, assim, que os tempos iniciais de desenvolvimento da linguagem do cinema faziam uso de referências intermidiáticas literárias. Quando o cinema alcançou autonomia semiótico-comunicativa, suas ampliadas possibilidades de expressão começaram a interessar à literatura, que passou a fazer uso de referências intermidiáticas fílmicas. ${ }^{6}$

As novidades expressivas cinematográficas instauraram-se gradualmente, mas se fizeram inevitavelmente notar com o surgimento de situações óticas puras, isto é, desprovidas de expedientes orientadores do olhar do espectador, que orientem o olhar ou lhe indiquem conexões entre as imagens contempladas, por meio de ações que promovam a continuidade e a ilusão da totalidade centrada no sujeito das ações. O espectador, nos primeiros anos do cinema, identificado com o personagem-sujeito, acompanhava-lhe o trabalho de costura ou coesão e confirmava sua ilusão totalizadora da realidade. Agora, contudo,

[...] a personagem tornou-se uma espécie de espectador. Por mais que se mexa, corra, agite, a situação em que está extravasa, de todos os lados, suas capacidades motoras, e lhe faz ver e ouvir o que não é mais passível, em princípio, de uma resposta ou ação. Ele registra, mais que reage. Está entregue a uma visão [...] (DELEUZE, 2005, p. 11).

Segundo Deleuze, o cinema de visualidade pura, proposto pelo neorrealismo italiano e praticado amplamente pelo cinema europeu, já não se propunha como meio de produção ou aperfeiçoamento da ilusão, como fábrica de sonhos, a reiterar nossos anseios por totalidade e protagonismo humano. Esse cinema aportou uma nova forma de pensamento que articulava no tempo, visualidades sem expedientes de conexão. A cada imagem exibida autonomamente (fora de uma cadeia significativa evidenciada), fez-se necessária a evocação, no intervalo interpretativo (por falta de conexão), de uma imagem virtual feita de memória, fruto da experiência armazenada que o pensamento resgata (como lembrança do repertório cognitivo e, especificamente, como

\footnotetext{
${ }^{6}$ As relações históricas entre cinema e literatura foram objeto de reflexão em outro artigo: MATTOS, Cristine Fickelscherer de. Film narrative in contemporary literature: an Argentinian example. Revista todas as letras (MACKENZIE. Online), São Paulo, v. 19, no 1, p. 1-11, 2017.
}

doi http://dx.doi.org/10.35572/rlr.v9i3.1866 


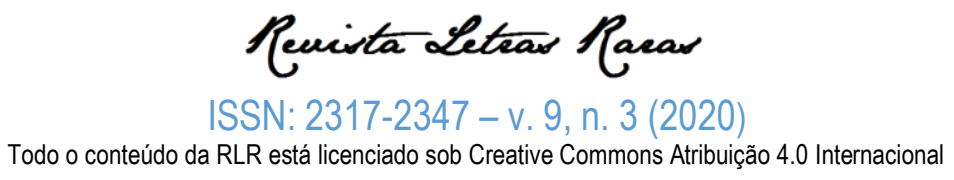

lembrança das imagens precedentes de um filme). Sabe-se que uma regra de ouro da criação para o cinema é a escrita roteirística sempre em tempo presente porque a expressão fílmica não pode ocorrer senão pelo ato de presenciar cenas. A visualidade é, pois, sempre presente, mas esse presente sempre muda, sendo substituído, sucessivamente, por outro presente. Assim, cada momento tem sua face atual como percepção presente e sua face virtual como lembrança (DELEUZE, 2005). O resgate evocativo de imagens precedentes do filme é fatalmente subjetivo tanto para o personagem quanto para o espectador. A subjetividade é mais intensa quanto mais autônoma a imagem, ou seja, quanto mais descontextualizada. Como ensinam os manuais de linguagem audiovisual, os enquadramentos mais próximos, conferem carga subjetiva maior à imagem, pela ausência de elementos contextuais: a imagem de um rosto, do plano próximo ao big close-up ou ao plano detalhe de alguma parte desse rosto, exige maior esforço interpretativo do personagem que eventualmente interage com o dono do rosto e também do espectador, que precisa criar mentalmente ligações espaço-temporais com as imagens anteriores do filme.

Em Barba ensopada de sangue, a prosopagnosia do protagonista cria oportunidades narrativas para a produção de situações óticas puras nas quais tanto personagem quanto leitor precisam resgatar imagens virtuais para o processamento interpretativo das imagens. Por tratarse de uma referência intermidiática em terreno literário e não de uma visualidade de fato, o texto precisa do artifício da deficiência neurológica, no caso do personagem, e da ausência de antecedentes narrativos no caso do leitor, uma vez que, assim como no trecho inicial, outros fragmentos em que o narrador descreve as visualidades desconexas de rostos percebidos pelo protagonista, carecem igualmente de informações precedentes por iniciarem uma seção ou introduzirem nova situação. Em função das limitações comunicativas próprias da linguagem literária, a narrativa pratica visualidades puras, mas sabe que precisa de conexões verbais que compensem a impossibilidade de reproduções totais da imagem pela palavra. Tal o motivo para que após momentos que imitam a visualidade pura, como mencionado, as relações de sentido sejam reveladas pelo narrador.

O narrar com situações óticas puras provoca o que Deleuze chama de imagem-tempo, entendida como pensamento que significa imagens pela sua articulação no tempo, que decodifica a imagem presente no fluxo temporal pela evocação de imagens passadas às quais se adere e ressignifica, ao representificá-las. Praticando a referenciação intermidiática do sistema semióticocomunicativo dos meios fílmicos - em sua parte imagética -, o romance de Galera aqui analisado, ao reunir impressões visuais do protagonista, esparsamente vinculadas a subpartes do enredo, 


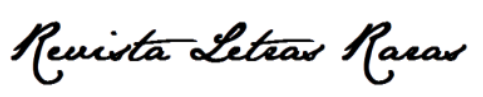

ISSN: 2317-2347 - v. 9, n. 3 (2020)

Todo o conteúdo da RLR está licenciado sob Creative Commons Atribuição 4.0 Internacional

simula a articulação imagem-tempo do cinema europeu do século XX. Como uma montagem a desafiar as habilidades interpretativas do leitor, o romance apresenta diferentes realidades marcadas por momentos fortemente imagéticos: a relação do protagonista com o pai apaixonado pela cachorra; a busca pelo avô briguento e invencivel, os dias de ermitão, perdido na floresta; a difícil e traumática relação com as mulheres. Todos esses subenredos estão evocados e ressignificados pela imagem que vem destacada no título e que aparece na narrativa perto do final: "Põe a mão em volta do queixo e espreme a barba ensopada de sangue de cima a baixo, até a ponta, fazendo escorrer um filete rubro que forma uma pequena poça nas lajotas brancas do pavimento" (GALERA, 2012, p. 389). A sequência de planos fechados (medium shot framesBORDWELL; THOMPSON, 2008, p. 191) - "a mão no queixo", "o espremer da barba", "o escorrer do filete de sangue", "o sangue empoçado na lajota" - formam um conjunto de imagens que, embora possuam ligação sequencial entre si, estão isoladas da cena em que se inseria 0 protagonista: uma briga de bar pela disputa da cachorra. É como se o enredo fizesse uma pausa em sua sequência de ações (em suas imagens-movimento) para dar lugar à imagem-tempo que evocará e ressignificará as imagens dos subenredos transformados em memória imagética do leitor e em memória afetiva do personagem. A barba ensopada de sangue estará sobreposta à lembrança da barba do pai e de sua paixão pela cachorra que agora provoca a briga do filho; à evocação da barba do avô violento e briguento escondido na floresta que agora coincide com a atitude do neto; ao resgate dos dias em que lhe cresceu a barba por estar perdido na floresta, ressignificados agora como retiro existencial transformador; à presença de Dália na cena da briga, que o leva ao hospital e remete à relação do personagem com as mulheres que reclamam da barba (a mãe, a namorada). Simulando na literatura os modos comunicativos da linguagem fílmica, o romance articula a imagem-tempo por meio dessa situação ótica principal ressaltada pelo título e em outras passagens pontuais menos relevantes.

\section{Considerações finais}

Como pudemos ver, o interesse pelos expedientes da linguagem cinematográfica, como tematizado no romance anterior Mãos de cavalo - "Era ele quem operava a câmera, quem saía da cena, atravessava a membrana entre a realidade e a imaginação e escolhia uma cadeira na plateia vazia de um cinema escuro" (GALERA, 2016, p 139-40) - passam do comentário à 


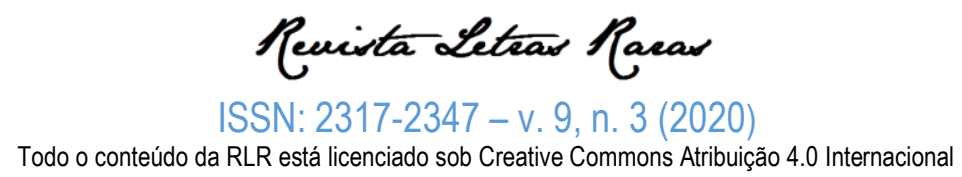

execução em Barba ensopada de sangue, através da referenciação intermidiática fílmica, tomada como sistema semiótico-comunicativo. O romance, com a adoção de modos perceptivos e cognitivos próprios da linguagem fílmica, demonstra assim consciência do peso dessa linguagem para a cultura atual e para os processos criativos literários contemporâneos. Mais do que um recurso estilístico de inovação, a presença de elementos de intermidialidade fílmica no romance Barba ensopada de sangue é a expressão de um pensamento cinemático que conforma a comunicação num mundo dominado por imagens em movimento nos mais banais atos do cotidiano; é a expressão também da subjetividade daquele que, em meio a esse mundo, contempla imagens e se vê como imagem. Se já se afirmou que o pensamento é verbal, por que não pode ser visual?

Ao contrário daqueles que viram no romance defeitos, vejo inovações e virtudes. No fluxo da história, também a literatura do presente evoca a literatura do passado, mas pode fazê-lo para ressignificar o passado em lugar de, por contraste e nostalgia, desmerecer o presente. A literatura do passado foi mais fonte de referências para o cinema que seguidora de seus procedimentos comunicativos. A partir de meados do século XX, o vetor se inverte parcialmente (pois a adaptação de filmes para a literatura é ainda incipiente) e a literatura vem bebendo das fontes audiovisuais para traduzir em arte verbal, por meio de referenciação fílmica, o espírito do nosso tempo.

\section{Referências}

ANA, Julián. Prosa pobre, pobre prosa. Rascunho. Fevereiro de 2013. Disponível em: http://rascunho.com.br/prosa-pobre-pobre-prosal. Acesso em 30 jun 2019.

ASSIS, Laura. A essencialidade dos "detalhes inúteis": estratégias de representação em Daniel Galera. Brasiliana - Journal for Brazilian Studies. London, vol. 3, no1, p 120-138, Jul. 2014. Disponivel em: https://tidsskrift.dk/bras/article/view/16734 Acesso em: 07 jun 2020.

BAETENS, Jan. La Novellisation. Du film au roman, Bruxelles: Les Impressions nouvelles, 2008.

BALÁZS, Béla. Early Film Theory: Visible Man and The Spirit of Film. Oxford: Berghahn, 2011.

BAZIN, André. O cinema: ensaios. São Paulo: Brasiliense, 1991.

BORDWELL, David; THOMPSON, Kristin. Film Art: An Introduction. New York: McGraw-Hill, 2008. COLOMBO, AGUILAR e SCHALLENBERGER. Mãos de prosa. Mínimo múltiplo, 06 de junho de 2011. Disponível em: www.minimomultiplo.com. Acesso em 30 jun 2019.

CUNHA, João M. dos S. A narrativa de Daniel Galera: mídias confundidas e relações intertextuais. Raído, Dourados, v. 5, no 10, p. 441-466, jul./dez. 2011. Disponível em: http://ojs.ufgd.edu.br/index.php/Raido/article/view/1383/1001. Acesso em 10 jul 2019.

doi) http://dx.doi.org/10.35572/rlr.v9i3.1866 


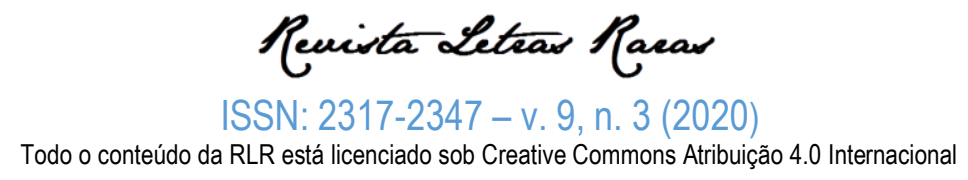

CUNHA, Martim Vasques da. A poeira da glória. Rio de Janeiro: Record, 2015.

DELEUZE, Gilles. A imagem-movimento. São Paulo: Brasiliense, 1985.

DELEUZE, Gilles. A imagem-tempo. São Paulo: Brasiliense, 2005.

EISENSTEIN, Sergei. Eisenstein Dickens, Griffith e nós. In: A forma do filme. Rio de Janeiro: Jorge Zahar, 2002a, p. 176-224.

EISENSTEIN, Sergei. Palavra e imagem. In: O sentido do filme. Rio de Janeiro: Jorge Zahar, 2002b, p 13-50.

FACCHIN, Michelle A. Barba ensopada de sangue: realismo e subjetividade. Revista de letras, v.17, n. 21, jul./dez. 2015. Disponível em: https://periodicos.utfpr.edu.br/rl/article/view/3033 Acesso em 10 jul 2019.

FIGUEIREDO, Vera. L. F. Entre o texto e a imagem: a literatura equilibrista. In: OLINTO, H. K. \& SCHØLLHAMMER, K. E. (orgs). Literatura e criatividade. Rio de Janeiro: 7Letras, 2012. p. 141154.

GALERA, Daniel. Barba ensopada de sangue. São Paulo: Cia da Letras, 2014.

GALERA, Daniel. Mãos de cavalo. São Paulo: Cia da Letras, 2016.

GRANDO, Diego e FURTADO, Lucas. A escrita imagética de Daniel Galera. Rebeca, vol 2, no 14, jul-dez 2018.

HUTCHEON, Linda. A Theory of Adaptation. New York: Routledge, 2006.

LETOUZÉ, Nathalie. A vida secreta das narrativas: técnicas narrativas na ficção contemporânea.

Tese da Universidade de Brasilia, 2019. Disponível em: https://repositorio.unb.br/bitstream/10482/37894/1/2019_NathalieLetouz\%c3\%a9Moreira.pdf.

Acesso em 09 jul 2019.

LEVY, Pierre. Tecnologias da inteligência: o futuro do pensamento na era da informática. São Paulo: 34 Letras, 2004.

MAGNY, Claude-Edmonde. L'Age du Roman Américain. Paris: Éditions du Seuil, 1949.

MAHLKNECHT, Johannes. The Hollywood Novelization: Film as Literature or Literature as Film Promotion? Poetics Today, Durham, EUA, vol 2,no 33, p 137-186, Summer 2012. Disponível em: https://rb.gy/an7bc9 Acesso em 30 jun 2020.

MURRAY, Edward. The Cinematic Imagination: Writers and the Motion Pictures. New York: Ungar, 1972.

RAJEWSKY, Irina. Intermidialidade, intertextualidade e remediação. In: DINIZ, T. F. N. (Org.). Intermidialidade e estudos interartes: desafios da arte contemporânea. Belo Horizonte: Editora UFMG, 2012. p 15-45.

RIPPL, Gabriele. Introduction. In: RIPPL, Gabriele (ed). Handbook of Intermediality. Boston: De Gruyter, 2015, p 1-32.

SANTOS, Alberto M. dos. Barba ensopada de sangue: um estudo. Albertosantos.org/literatura, 05 de agosto de 2015.2 Disponível em: http://www.albertosantos.org/Barba\%20ensopada\%20de\%20sangue.html Acesso em 09 set 2019. 


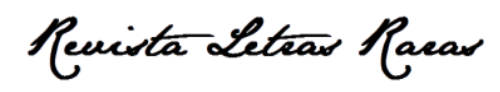

ISSN: 2317-2347 - v. 9, n. 3 (2020)

Todo o conteúdo da RLR está licenciado sob Creative Commons Atribuição 4.0 Internacional

SCHØLLHAMMER, Karl Erick. Barbas de molho. Cult, ed. 174, 8 nov. 2012a. Disponível em: https://resenhasbrasil.blogspot.com/2013/12/barba-ensopada-de-sangue.html?m=0. Acesso em 09 set 2019.

SCHØLLHAMMER, Karl Erick. Realismo afetivo: evocar realismo além da representação. Estudos de literatura brasileira contemporânea, Universidade de Brasília, Brasília, n.39, p. 11-17, jan/jun. 2012b.

SCHØLLHAMMER, Karl Erick. Ficção brasileira contemporânea. Rio de Janeiro: Civilização Brasileira, 2009.

SCHWANECKE, Christine. Filmic Modes in Literature. In: RIPPL, Gabriele (ed.). Handbook of Intermediality. Boston: De Gruyter, 2015, p 268-285.

SCHWEIGHAUSER, Philipp. Literary Acoustics. In: RIPPL, Gabriele (ed.). Handbook of Intermediality. Boston: De Gruyter, 2015, p 475-493.

STAM, Robert. Teoria e prática da adaptação. Iha do desterro, Florianópolis, n 52, p 19-53, juldez 2006.

VIGNA, Elvira. Barbas nada confiáveis. Études Lusophones , 23 novembro 2012 Disponível em: http://etudeslusophones.blogspot.com/2012/11/barbas-pouco-confiaveis.html Acesso em 15 out 2019. 